\title{
Relationship between Body mass index (BMI) and body fat percentage, estimated by bioelectrical impedance, in a group of Sri Lankan adults: a cross sectional study
}

Chathuranga Ranasinghe ${ }^{1,2^{*}}$, Prasanna Gamage ${ }^{1}$, Prasad Katulanda², Nalinda Andraweera', Sithira Thilakarathne ${ }^{2}$ and Praveen Tharanga ${ }^{1}$

\begin{abstract}
Background: Body Mass Index (BMI) is used as a useful population-level measure of overweight and obesity. It is used as the same for both sexes and for all ages of adults. The relationship between BMI and body fat percentage (BF \%) has been studied in various ethnic groups to estimate the capacity of BMI to predict adiposity. We aimed to study the BMI-BF\% relationship, in a group of South Asian adults who have a different body composition compared to presently studied ethnic groups. We examined the influence of age, gender in this relationship and assessed its' linearity or curvilinearity.

Methods: A cross sectional study was conducted, where adults of 18-83 years were grouped into young (18-39 years) middle aged (40-59 years) and elderly ( $>60$ years). BF\% was estimated from bioelectrical impedance analysis. Pearsons' correlation coefficient $(r)$ was calculated to see the relationship between BMI-BF\% in the different age groups. Multiple regression analysis was performed to determine the effect of age and gender in the relationship and polynomial regression was carried out to see its' linearity. The relationships between age-BMI, age-BF \% were separately assessed.

Results: Out of 1114 participants, $49.1 \%$ were males. The study sample represented a wide range of BMI values $\left(14.8-41.1 \mathrm{~kg} / \mathrm{m}^{2}\right.$,Mean $\left.23.8 \pm 4.2 \mathrm{~kg} / \mathrm{m}^{2}\right)$. A significant positive correlation was observed between BMI-BF\%, in males $(r=0.75, p<0.01$; SEE $=4.17)$ and in females $(r=0.82, \mathrm{p}<0.01$; SEE $=3.54)$ of all ages. Effect of age and gender in the BMI-BF\% relationship was significant $(p<0.001)$; with more effect from gender. Regression line found to be curvilinear in nature at higher BMI values where females $(p<0.000)$ having a better fit of the curve compared to males $(p<0.05)$. In both genders, with increase of age, BMl seemed to increase in curvilinear fashion, whereas BF\% increased in a linear fashion.

Conclusions: BMI strongly correlate with BF \% estimated by bioelectrical impedance, in this sub population of South Asian adults. This relationship was curvilinear in nature and was significantly influenced by age and gender. Our findings support the importance of taking age and gender in to consideration when using BMI to predict body fat percentage/obesity, in a population.
\end{abstract}

Keywords: Body mass index, Body fat, Bioelectrical impedance, Sri Lanka, Adults, Age, Sex

\footnotetext{
*Correspondence: chath_r@yahoo.com.au

'Allied Health Sciences Unit, Faculty of Medicine, University of Colombo, PO box 25, Kynsey road, Colombo 10, Sri Lanka

${ }^{2}$ Diabetes Research Unit, Faculty of Medicine, University of Colombo, PO box 25, Kynsey road, Colombo 10, Sri Lanka
} 


\section{Background}

Overweight and obesity are defined as abnormal or excessive fat accumulation in the body that may impair health [1]. During the last few decades, the prevalence of obesity has increased and has become a considerable global health hazard [2,3]. Excessive body fat is associated with increased metabolic risk, and its' measurement is important in implementing curative and preventive health measures. Direct measurement of body fat requires sophisticated equipment and is time consuming, it is also difficult in epidemiological studies [4]. The most commonly used surrogate measure for prediction of body fat percentage (BF\%) is Body Mass Index (BMI) [5-8]. How ever some studies have shown, that they (BMI-BF\%) have an imperfect association [9] and some in contrast justify a strong association [5,6,9-12]. Some even have described the linear [6] or curvilinear [8,9] nature of this relationship.

World Health Organisation (WHO) also recommends BMI as the most useful population level measure of overweight and obesity, and is used as the same for both sexes and in all ages of adults [1]. So BMI of $>25 \mathrm{~kg} / \mathrm{m}^{2}$ and $>30 \mathrm{~kg} / \mathrm{m}^{2}$ are considered to be overweight and obese in adults irrespective of gender and age. This use of a single standard for obesity for all adults was recommended because it is thought to be independent of age and it can be used for making comparisons across studies [13]. At present, there are studies conducted in various ethnic groups to determine the effect of age and gender $[14,15]$ in the BMI -BF\% relationship, and there are uncertainties about the final conclusion [9]. Published data on this topic is limited in South Asians, who have relatively high $\mathrm{BF} \%$ and increased cardiovascular risk compared to other ethnic groups [16].

We used Bioelectrical Impedance Analysis (BIA) method to estimate the Body fat \%. BIA is known to provide a rapid, non-invasive and relatively accurate measurement of body composition [17] with the possibility of utilizing at field settings. BIA methods validity has been tested, taking $\mathrm{BF} \%$ as the outcome variable; with a range of reference techniques including, total body water hydrodensitormetry, dual energy X-ray absorptiometry and air displacement plethysmography $[9,18]$. Large population studies conducted even have provided reference values of body composition based on bioelectrical impedance analysis [19].

So we studied a large sub-population of South Asian adults from Sri Lanka; to determine the relationship between BMI and BF \%, and then to identify the nature of the relationship, whether linear or curvilinear. We also tried to find the effects of age and gender on this relationship. We wish to present our results which would add more evidence to the ongoing discussion; as they were derived from an ethnic group which was not studied before.

\section{Methods}

\section{Study population}

The study was designed as a cross-sectional (population) study. The participants were randomly recruited (every 3rd person who volunteered) from those attending a research center located in an exhibition venue during a medical exhibition conducted by, Faculty of Medicine, University of Colombo Sri Lanka in 2008. Adults above the age of 18 years with no other physical disease were included. Pregnant women were excluded. Height, weight and body composition measurements were carried out by a group of medical graduates after supervised training. Inter-observer/operator reliability was assured. Informed written consent was taken from all participants. Confidentiality was maintained during the storage, retrieval and analysis of data. Ethical approval was taken by Ethics Review Committee Faculty of Medicine University of Colombo Sri Lanka.

\section{Body composition measurements Anthropometry}

Measurements were taken using standardized equipment. Height of all participants were measured using a stadiometer (seca 206, Germany) in standing position without footwear to the nearest $0.1 \mathrm{~cm}$. Weight was measured with minimum clothes using a calibrated electronic scale with digital readout (seca 808, Germany) to the nearest $0.1 \mathrm{~kg}$. BMI was calculated by weight $(\mathrm{kg})$ divided by height $(\mathrm{m})$ squared $\left(\mathrm{kg} / \mathrm{m}^{2}\right)$.

\section{BIA derived percent body fat}

Total body fat percentage (BF \%) was estimated by using a commercially available single-frequency, 8 electrode bio impedance analyzer system (BC-418, Tanita Corp, Tokyo, Japan). The reliability and validity of this system in measuring $\mathrm{BF} \%$ has been previously verified in multiple ethnicities [20,21]. All measurements were taken during morning hours (0830-1200) and the subjects didn't have any vigorous activity during the preceding 12 hours of the measurement. The system consisted of two handgrips with two electrodes each and a footplate with four electrodes. All procedures carried out according to manufacturer instructions [20]. The electrodes between the left and right grips were short-circuited, along with those for the left and right feet. Study subjects stood on the footplate and gently grasped the two handgrips with arms held straight forward at 90 degrees. During the measurement, the instrument recorded whole body impedance from the hands to the feet by applying an electric alternating current flux of $0.8 \mathrm{~mA}$ at an operating frequency of $50 \mathrm{kHz}$. Finally, BF\% was calculated from the whole body impedance value and the pre-entered personal data (age, gender, height and weight) of the corresponding subject. BF\% was estimated to the nearest $0.1 \%$. Inter-observer /operator reliability 
and precision of impedance measurements in the same subjects under standard condition were monitored. Wholebody composition was estimated using standard equations provided by the BIA manufacturer.

\section{Statistical analysis}

Subjects were grouped into males and females. Then each gender was grouped as young (18-39 years) middle age (40-59 years) and elderly (>60 years). Basic descriptive statistics for subject data were expressed as means \pm standard deviations. Differences between means were separated by one way ANOVA.

Pearsons' correlation coefficients $(r)$ were calculated to assess the link and the degree of relation between BMI and $\mathrm{BF} \%$, in relation to gender and age variables. Multiple regression analysis was performed to examine the possible effect of gender on the relationship between $\mathrm{BMI}$ and $\mathrm{BF} \%$. Then age was further added to the model to see its' effect. BMI, age and gender were taken as independent variables and $\mathrm{BF} \%$ as the dependent variable.

Polynomial regression analysis examined the linearity of the BMI-BF\% relationship. General linear model analysis was first used. Then it was extended to examine nonlinearity by including a quadratic term for BMI $\left(\mathrm{BMI}^{2}\right)$. Variance of BF\% was estimated for general linear modal; and after adding the quadratic term. This was performed in males and females separately. Visual inspection of the relationship (BMI-BF \%) was also made. Distribution and linearity of age-BMI and age-BF\% relationships were separately assessed. Statistical analysis of data was carried out using the SPSS version 16.0 (SPSS Inc. USA) software for Windows.

\section{Results}

\section{Baseline group characteristics}

A total of 1114 adults were investigated during the study; $49.1 \%$ were males (Table 1 ). The study sample represented a wide range of BMI values $\left(14.8-41.1 \mathrm{~kg} / \mathrm{m}^{2}\right)$. Ninety four percent $(94 \%)$ of the total sample had BMI values $<30 \mathrm{~kg} / \mathrm{m}^{2}$ (Mean $23.8 \pm 4.2 \mathrm{~kg} / \mathrm{m}^{2}$ ).

\section{Relationship between $\mathrm{BMI}$ and BF\%}

There was a strong and significant positive correlation between BMI- BF\% in males $(r=0.75, \mathrm{p}<0.01 ; \mathrm{SEE}=4.17)$ and in females $(r=0.82, \mathrm{p}<0.01 ; \mathrm{SEE}=3.54)$. Correlations calculated for the three different age groups separately, also showed the significance $(\mathrm{p}<0.01)$.In males/females they were, $r=0.79 / 0.84$ (young), $r=0.71 / 0.70$ (middle age), $r=0.59 / 0.075$ (elderly) respectively.

\section{The effect of age and gender in the BMI -BF\% relationship}

Age and gender were found to be significant predictor variables in the regression models $(\mathrm{p}<0.000)$ (Tables 2 and 3 ), where gender contributing more effect to the relationship (Model 2).

\section{Linearity/curvilinearity of the BMI -BF\% relationship}

Visual inspection of the scatter plot (Figure 1) also showed the positive relationships between the BF \% and BMI. It revealed that the relationship appears to be linear in nature and curvilinearity developing towards the high BMI values. Polynomial regression which was carried out to test for linearity in both males and females showed a significant quadratic component. The BMI linear component accounted for $67.5 \%$ of the female variance and $57.6 \%$ of the male variance. Adding the quadratic component accounted for an additional $2.9 \%$ of the female variance $(\mathrm{p}<0.000)$ and $2.2 \%$ of the male variance $(\mathrm{p}<0.01)$. The female model $\left(R^{2}=0.70\right.$,SEE $\left.3.4 \%\right)$ provided more accurate fit than the male model $\left(R^{2}=0.58\right.$, SEE $\left.4.1 \%\right)$. This confirmed that the relationship between BMI-BF\% measured by bioelectrical impedance for this Sri Lankan group of adults was curvilinear.

\section{Independent relationship of age on $\mathrm{BMI}$ and $\mathrm{BF} \%$}

BMI noted to increase with age in young; relatively constant in middle age and decline in elderly in both males and females (Figure 2). This curvilinear effect was more significant in females $\left(R^{2}=0.27, R^{2}\right.$ change $=0.058$, SEE $11.5 \%)(\mathrm{p}=<0.000)$ compared to males $\left(\mathrm{R}^{2}=0.61, \mathrm{R}^{2}\right.$ change $=0.009$,SEE $13.7 \%)(\mathrm{p}=<0.05)$. Females had a significantly higher mean BMI values than males in all

Table 1 Male and female characteristics (mean \pm SD) contrasted by age group

\begin{tabular}{|c|c|c|c|c|c|c|}
\hline \multirow[t]{2}{*}{ Variable } & \multicolumn{3}{|c|}{ Male $(n=547)$} & \multicolumn{3}{|c|}{ Female $(n=567)$} \\
\hline & $\begin{array}{l}\text { Young } \\
(n=279)\end{array}$ & $\begin{array}{l}\text { Middle-age } \\
(\mathrm{n}=232)\end{array}$ & $\begin{array}{l}\text { Elderly } \\
(n=36)\end{array}$ & $\begin{array}{l}\text { Young } \\
(n=260)\end{array}$ & $\begin{array}{l}\text { Middle-age } \\
(\mathrm{n}=279)\end{array}$ & $\begin{array}{l}\text { Elderly } \\
(n=28)\end{array}$ \\
\hline Age (y) & $26.7 \pm 6.6$ & $48.4 \pm 5.3$ & $65.9 \pm 6.5$ & $25.9 \pm 7.2$ & $47.3 \pm 4.9$ & $64.6 \pm 5.0$ \\
\hline Height $(\mathrm{cm})$ & $168.7 \pm 6.2$ & $165.9 \pm 6.0$ & $162.2 \pm 5.5$ & $156.5 \pm 5.8$ & $155.1 \pm 5.6$ & $152.1 \pm 6.8$ \\
\hline Weight (kg) & $64.9 \pm 12.1$ & $68.2 \pm 11.4$ & $60.5 \pm 11.9$ & $53.6 \pm 11.4$ & $62.4 \pm 10.1$ & $57.4 \pm 24.7$ \\
\hline $\mathrm{BMI}\left(\mathrm{kg} / \mathrm{m}^{2}\right)$ & $22.7 \pm 3.8$ & $24.6 \pm 3.5$ & $22.8 \pm 3.9$ & $21.8 \pm 4.3$ & $26.1 \pm 3.8$ & $24.7 \pm 3.5$ \\
\hline Body fat $\%$ & $19.5 \pm 6.6$ & $24.5 \pm 4.6$ & $24.4 \pm 5.5$ & $28.0 \pm 6.0$ & $34.7 \pm 4.3$ & $36.7 \pm 4.8$ \\
\hline
\end{tabular}

Continuous variables (Age, Height, Weight, BMI-Body Mass Index, Body Fat\%) are given as mean values with their standard deviations (SD). Number of participants (n). 
Table 2 Multiple regression analysis for change in BF\% with BMI, age for males and females (Model 1)

\begin{tabular}{|c|c|c|c|c|c|c|}
\hline & \multicolumn{3}{|l|}{ Male } & \multicolumn{3}{|l|}{ Female } \\
\hline & Intercept/Regression coefficients $/ \mathrm{R}^{2}$ & SE & Beta & Intercept/Regression coefficients $/ \mathrm{R}^{2}$ & SE & Beta \\
\hline Intercept & -9.662 & 1.011 & & -3.819 & 0.688 & \\
\hline BMI & 1.114 & 0.043 & $0.678(p<0.000)$ & 0.918 & 0.032 & $0.670(p<0.000)$ \\
\hline Age & 0.139 & 0.012 & $0.313(p<0.000)$ & 0.153 & 0.011 & $0.331(p<0.000)$ \\
\hline$R^{2}$ & 0.654 & & & 0.764 & & \\
\hline
\end{tabular}

SE: Standard Error, BMI: Body mass index, $R^{2}$ : squared regression coefficients.

three age group categories except in young (age 1839 years $)(\mathrm{p}<0.05)$ (Table 1$)$.

In both males and females $\mathrm{BF} \%$ showed an increase with age (Figure 3) with a positive linear correlation (males $r=0.47$, females $r=0.64 ; \mathrm{p}<0.000$ ). Females of all ages had significantly higher total body fat than males $(\mathrm{p}<0.001)$ (Table 1). The mean difference in $\mathrm{BF} \%$ between females and males was 10.44.This difference was shown to increase with age (young 8.5, middle-age 10.2 and elderly 12.3) (Table 1).

\section{Discussion}

Our study mainly tried to answer 2 questions, which were; (1) what is the relationship between BMI and BF $\%$ ( measured by BIA)? And (2) what is the effect of age and gender in this relationship?, in a sub-population of South Asian adults. This was to determine the predictive value of $\mathrm{BMI}$ as a measure of $\mathrm{BF} \%$ in adults, and to show any significance of age and sex in this prediction, which is not considered by WHO [1] at present when commenting obesity. Most researchers have tried to answer these questions in different populations and ethnic groups [3-7]. Some have also studied the predictive effect of racial difference in this (BMI- BF \%) relationship [5,22]. We analysed data from a group of native Sri Lankan adults who are categorized as South Asians (who are similar to Asian Indians), who have a different body composition compared to Caucasians, Blacks and even Asian Mongolians [22-24]. We hope that answers to the above questions provided by this different ethnic group, would further add strength to the current pool of evidence regarding the relationship between BMI and BF\%.

Table 3 Multiple regression analysis for change in BF\% with BMI, age and gender (Model 2)

\begin{tabular}{lcccc}
\hline & Intercept/Regression coefficients $/ \mathbf{R}^{\mathbf{2}}$ & $\mathbf{S E}$ & Beta & $\mathbf{p}$ \\
\hline Intercept & -16.563 & 0.651 & $<0.000$ \\
$\mathrm{BMl}$ & 1.004 & 0.026 & 0.532 & $<0.000$ \\
Age & 0.143 & 0.008 & 0.248 & $<0.000$ \\
Gender & -9.343 & 0.204 & 0.586 & $<0.000$ \\
$\mathrm{R}^{2}$ & 0.818 & & & $<0.000$ \\
\hline SE: Standard Ero
\end{tabular}

SE: Standard Error, BMI: Body mass index, $R^{2}$ : squared regression coefficient.
The use of different methods to estimate BF\%; their validity, reliability have been discussed in variety of studies [25-27]. We used bioelectrical impedance analysis method (BIA) to estimate the BF\% of our subjects. The use of BIA as a safe, valid and feasible tool is been accepted $[17,19]$ and the equipment we used (BC-418, Tanita Corp, Tokyo, Japan)has been validated in past population based studies in different ethnic groups $[20,21]$.

Our study confirmed the significant positive relationship between BMI and BF\% which was demonstrated in most of the former studies. This was observed in both males and females separately and in each age group (young, middle-age and elderly). An early study by P. Deurenberg [7] done in Caucasians, this interaction was significant; whereas Jackson et al. [5] who compared Caucasians with Blacks reported the same. Rush et al. [22] who studied European, Maori, Pacific Islanders and Asian Indian adults also confirmed the significant positive relationship in BMI-BF\% in all these races. More recent large study by S. Meeuwsen [9] using UK adults has shown that the association is not especially good. This is particularly so when BMI is less than $25 \mathrm{~kg} / \mathrm{m}^{2}$, particularly in men. BMI values of most of our participants were between $20-30 \mathrm{~kg} / \mathrm{m}^{2}$, whereas the BMI range varied among other studies. The reasons for these discrepancies observed in these cross sectional studies, said to be unknown and assumed to be due to, the use of different body composition methodology as well as biological differences in the characteristics of the study populations [9].

This study also tried to answer a controversial issue of linearity/curvilinearity of the studied relationship (BMI$\mathrm{BF} \%)$. Some former studies have shown the relationship as linear [6] and some as curvilinear/ quadratic [8,9]. Curvilinearity was mostly observed when the subjects of the samples had higher BMI values $\left(35 \mathrm{~kg} / \mathrm{m}^{2}\right.$ or more) $[8,9]$. Study by Rush et al. described the relationship to be curvilinear, in Europeans (mean BMI $25 \cdot 8 \mathrm{~kg} / \mathrm{m}^{2}$, range $20 \cdot 0$ $36 \cdot 2)$, in Maori $\left(30 \cdot 4 \mathrm{~kg} / \mathrm{m}^{2} / 18 \cdot 9-43 \cdot 5\right)$, in Pacific Island $\left(31 \cdot 3 \mathrm{~kg} / \mathrm{m}^{2} / 17 \cdot 8-42 \cdot 2\right)$ and in Asian Indians $\left(26 \cdot 1 \mathrm{~kg} / \mathrm{m}^{2} / 16 \cdot 8-40 \cdot 2\right)$. But our total sample had $94 \%$ of the subjects having BMI values $<30 \mathrm{~kg} / \mathrm{m}^{2}$ (mean $23.8 \mathrm{~kg} / \mathrm{m}^{2}$, range $14.8-41.1 \mathrm{~kg} / \mathrm{m}^{2}$ ) and still showed a 


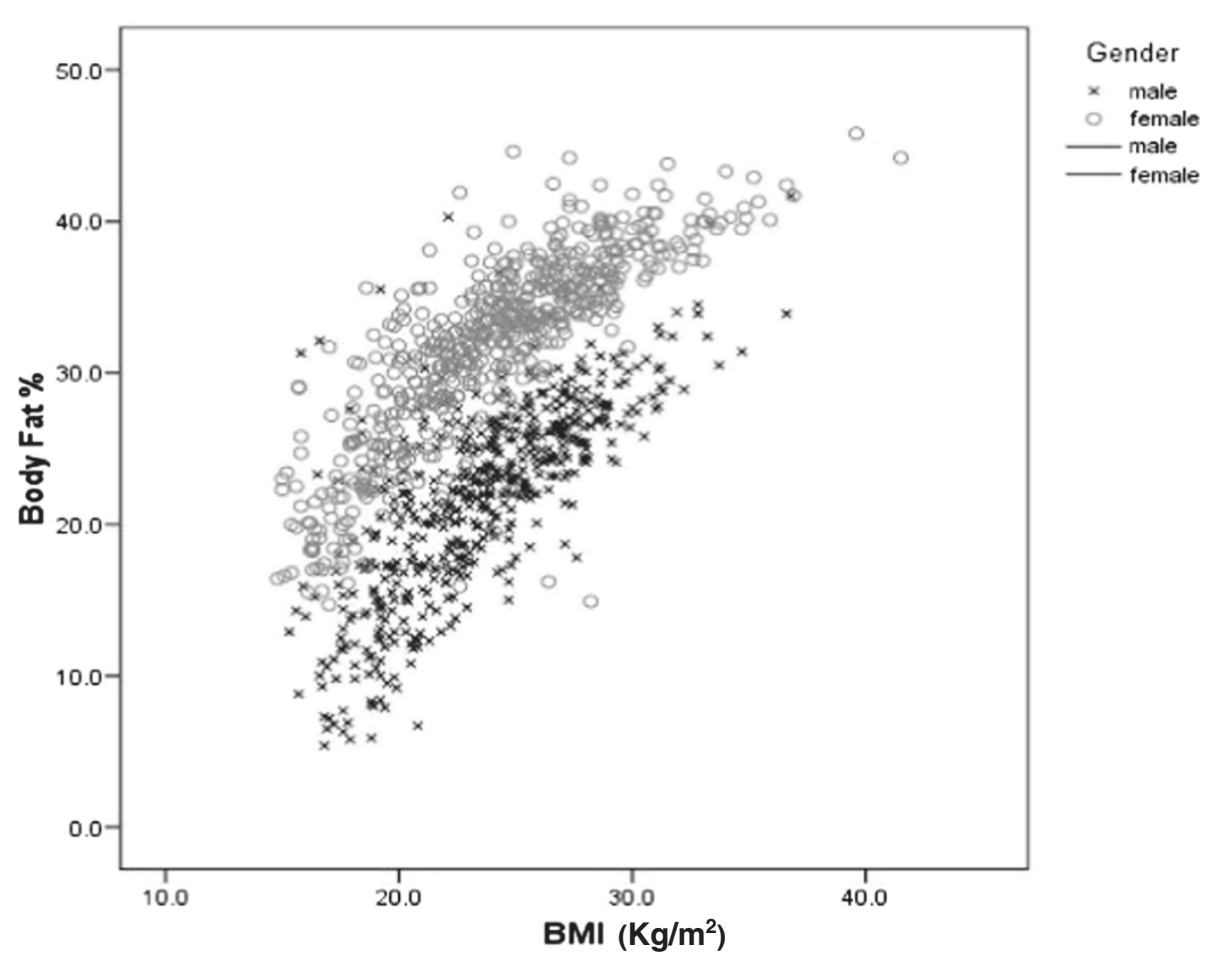

Figure 1 Scatter plot of the relationship between Body Mass Index (BMI) and percentage of body fat (BF\%) of Sri Lankan men (+) and women (o). Relationship between the percentage of body fat (BF \%) and body mass index (BMI) of Sri Lankan (+) males and (o) females. The linear regression models: $(\mathrm{BF} \%$ male $=(\mathrm{BMI} \times 1.114)+($ age $\times 0.139)-9.662$ and $\mathrm{BF} \%$ female $=(\mathrm{BMI} \times 0.918)+($ age $\times 0.153)+3.819$. Polynomial regression for non linearity: females $\left(R^{2}=0.70\right.$, SEE $\left.3.4 \%, p<0.000\right)$ males $\left(R^{2}=0.58\right.$, SEE $\left.4.1 \%, p<0.05\right)$.

curvilinear relationship. Females who had a better fit of the curvilinear curve had $8.8 \%$ of the population having BMI values $>30 \mathrm{~kg} / \mathrm{m}^{2}$. Males who had a lesser fit of the curve had $4.8 \%$. This shows the effect of curvilinearity with higher BMI values, which was discussed by other authors. But in this Sri Lankan population curvilinearity became significant in BMI values $<35 \mathrm{~kg} / \mathrm{m}^{2}$ (even less than $30 \mathrm{~kg} / \mathrm{m}^{2}$ ).

Multiple regression analysis conducted showed a significant effect of age and gender in the studied relationship (BMI- BF \%) with more effect from gender $(\operatorname{Beta}(\beta)=0.586, p<0.000)$. This effect of gender in the relationship is well documented in past studies $[5-7,14,28]$. The usual pattern in most populations was that, BF\% is greater in women than in men [9], which we also observed in the full range of BMI values $(\mathrm{p}<0.000)$. The effect of age was not studied previously as much as the effect of gender [5]. Our results confirmed the significant effect of age in the relationship which was consistent with the studies which did the same $[5-7,9,22]$. So we support the existing body of evidence that, when describing BMI values for prediction of BF\%, (or overweight/obesity) the effect of gender and age to be considered, clinically and in public health interventions.
When considering the individual effect of age on $\mathrm{BF} \%$ (age-BF \%), we observed when subjects got older there was a linear increase of $\mathrm{BF} \%$ in both sexes. But BMI increased with age (age-BMI) in a curvilinear manner, showing a reduction in BMI in elderly. So elderly subjects reduced $\mathrm{BMI}$ and increased $\mathrm{BF} \%$ at the same time. This may be due to sarcopenia, which is explained by progressive loss of muscle mass with age and accumulation of body fat [29]. These changes are attributed to physical inactivity, motor-unit remodeling, decreased hormone levels, and decreased protein synthesis which occur with aging $[29,30]$. Sri Lankans at the moment one of the fastest aging populations in the region [31] will need further research determining the effects of sarcopenia; and interventions on reversing sarcopenia and associated cardiovascular risk [32]. The mean difference in BF\% between males and females also increased with age, where females gained more fat than males when they became old. In this context, some of the interventions might have to be directed more towards females.

This study had several limitations. The sample was taken from a health conscious group of adults who attended a medical exhibition and we can't generalize these data to all Sri Lankans. We were not able to control some of the BIA measurement prerequisites as we relied on information 

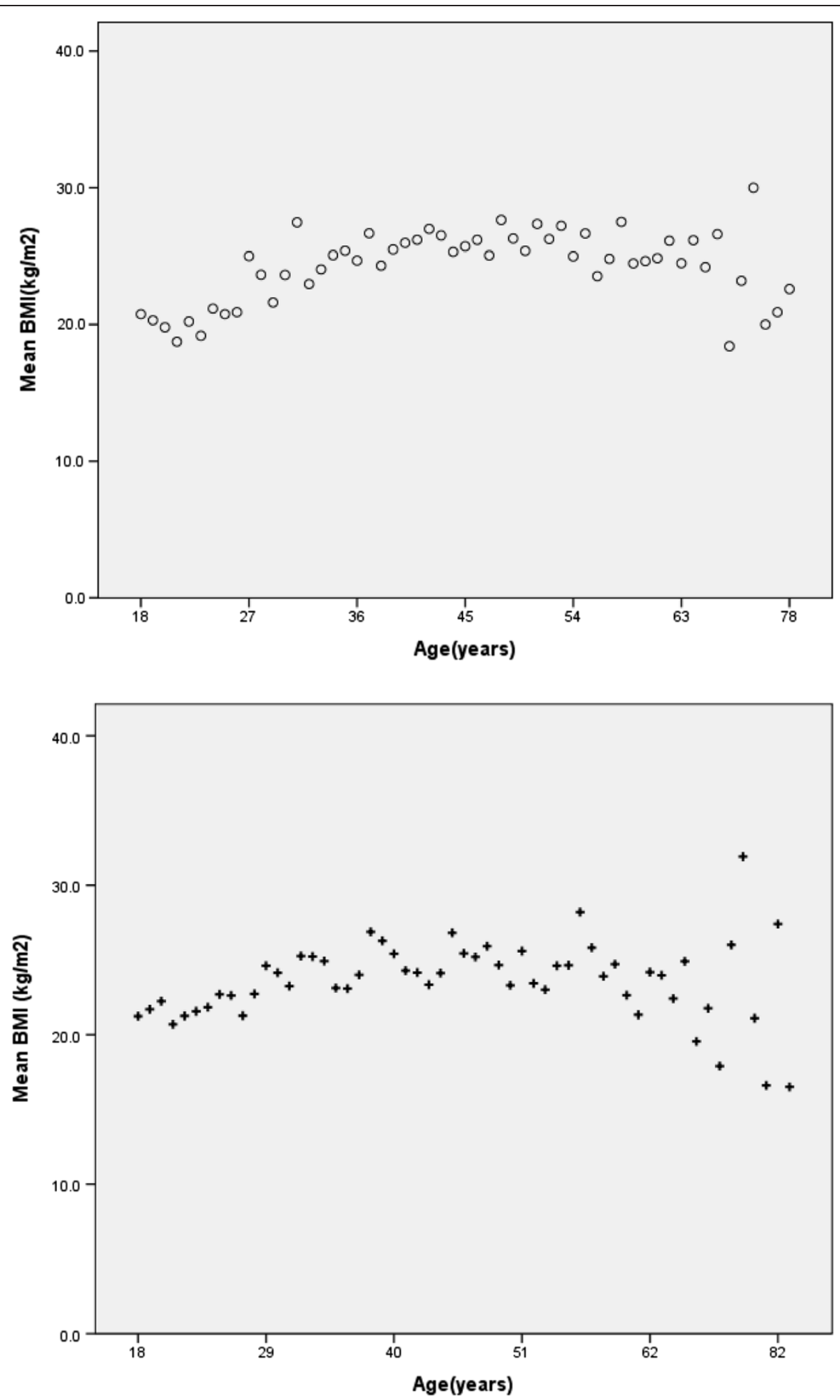

Figure 2 Relationship between BMI and age in (o) females (upper graph) and (+) males (lower graph). 

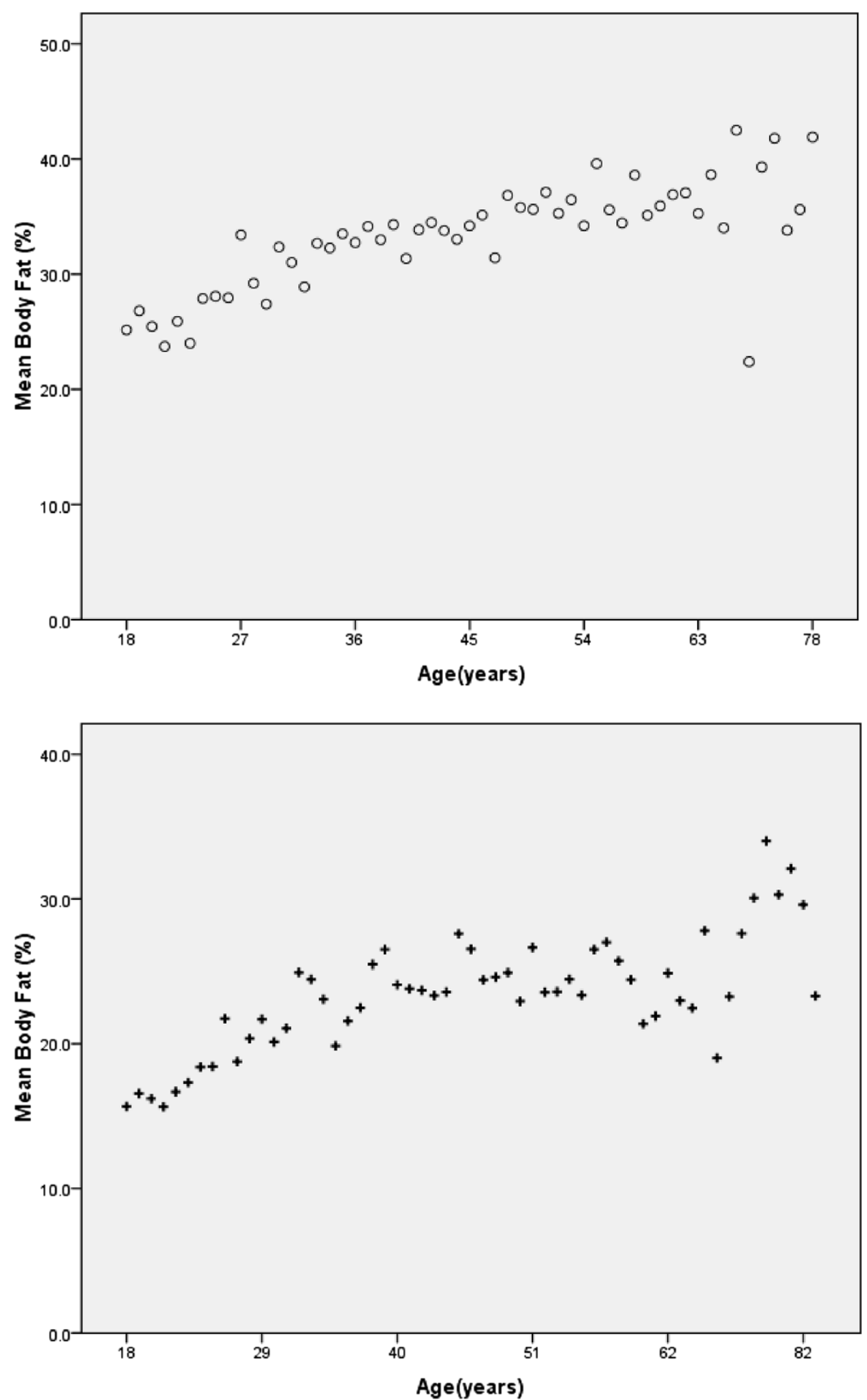

Figure 3 Relationship between percent body fat (BF\%) and age in (o)females (upper graph) and (+)males (lower graph).

given by the participants (E.g. Measurements should be taken patient fasting for 3 hours/not having vigorous activity for past 12 hours). But the results of the study were comparable to other studies done in more controlled subject samples. Yet another factor is the accuracy of bioelectrical impedance technique when compared with reference body composition measurement techniques (hydrodensitometry, water dilution technique) 
or multicomponent models. However, in epidemiological studies some degree of accuracy is sacrificed for simplicity, acceptability and rapid data acquisition [9].

\section{Conclusions}

Our results demonstrate that Body Mass Index (BMI) strongly correlates with body fat percentage (BF \%) estimated by bioelectrical impedance, in this group of South Asian adults from Sri Lanka. This relationship was curvilinear in nature even at BMI values $<30 \mathrm{~kg} / \mathrm{m}^{2}$. It was significantly influenced by age and gender of the individual where gender affected most. Therefore our findings support the importance of taking age and gender in to consideration when using BMI to predict body fat percentage/obesity, in a population.

\section{Abbreviations}

BMI: Body mass index; BF\%: Body fat percentage; BIA: Bioelectrical impedance analysis; WHO: World Health Organisation; UK: United Kingdom; SPSS: Statistical package for the social sciences.

\section{Competing interests}

The authors declare that they have no competing interests.

\section{Authors' contributions}

CR, PG participated in the design of the study, data collection, examining the participants, performed the statistical analysis and drafted the manuscript. PK, NA participated in its design and helped to draft the manuscript. ST, PT data collection, examining the participants and helped to draft the manuscript. All authors read and approved the final manuscript.

\section{Acknowledgements}

We thank Dr C. Thurairaja for providing the bioelectrical impedance analysis (Tanita, Japan) system for the study. Dr Ayodya Ranasighe, Dr Gavithra Dayananda for data collection and entry, examining the participants. Dr Ranil Jayawardena, Dr Priyanga Ranasighe, Dr Romain Perera for comments on draft manuscript.

Received: 24 December 2012 Accepted: 30 August 2013

Published: 3 September 2013

\section{References}

1. World Health Organization: Obesity and overweight: fact sheet $N^{0} 311 ; 2012$. http://www.who.int/mediacentre/factsheets/fs311/en/index.html.

2. World Health Organization: Obesity: preventing and managing the global epidemic; WHO consultation technical report series 894. Geneva; 2000.

3. James PT, Leach R, Kalamara E, Shayeghi M: The worldwide obesity epidemic. Obes Res 2001, 9(Suppl 4):228-233.

4. Vasudev S, Mohan A, Mohan D, Farooq S, Raj D, Mohan V: Validation of body fat measurement by skinfolds and two bioelectric impedance methods with DEXA-the Chennai Urban Rural Epidemiology Study [CURES-3]. J Assoc Physicians India 2004, 52:877-881.

5. Jackson AS, Stanforth PR, Gagnon J, Rankinen T, Leon AS, Rao DC, Skinner $J \mathrm{~S}$, Bouchard $\mathrm{C}$, Wilmore $\mathrm{JH}$ : The effect of sex, age and race on estimating percentage body fat from body mass index: the heritage family study. Int J Obes Relat Metab Disord 2002, 26(6):789-796.

6. Gallagher D, Visser M, Sepulveda D, Pierson RN, Harris T, Heymsfield SB: How useful is body mass index for comparison of body fatness across age, sex, and ethnic groups? Am J Epidemiol 1996, 143:228-239.

7. Deurenberg $P$, van der Kooy K, Hulshof T, Evers P: Body mass index as a measure of body fatness in the elderly. Eur J Clin Nutr 1989, 43:231-236.

8. Jackson AS, Pollock ML, Ward A: Generalized equations for predicting body density of women. Med Sci Sports Exerc 1980, 12(3):175-181.

9. Meeuwsen S, Horgan GW, Elia M: The relationship between BMI and percent body fat, measured by bioelectrical impedance, in a large adult sample is curvilinear and influenced by age and sex. Clin Nutr 2010, 29(5):560-566.

10. Gillette-Guyonnet S, Vellas B: Body composition and age-related diseases. Mech Ageing Dev 2003, 124(3):247-248.
11. Nass R, Thorner MO: Impact of the GH-cortisol ratio on the age-dependent changes in body composition. Growth Horm IGF Res 2002, 12(3):147-161.

12. Perry HM, Morley JE, Horowitz M, Kaiser FE, Miller DK, Wittert G: Body composition and age in African-American and Caucasian women: relationship to plasma leptin levels. Metabolism 1997, 46(12):1399-1405.

13. Kuczmarski RJ, Flegal KM: Criteria for definition of overweight in transition: background and recommendations for the United States. Am J Clin Nutr 2000, 72(5):1074-1081.

14. Womersley J: A comparison of the skinfold method with extent of 'overweight' and various weight-height relationships in the assessment of obesity. Br J Nutr 1977, 38(2):271-284.

15. Deurenberg-Yap M, Schmidt G, van Staveren WA, Deurenberg P: The paradox of low body mass index and high body fat percentage among Chinese, Malays and Indians in Singapore. Int $J$ Obes Relat Metab Disord 2000, 24(8):1011-1017.

16. Lear SA, Humphries $\mathrm{KH}$, Kohli S, Birmingham CL: The use of BMI and waist circumference as surrogates of body fat differs by ethnicity. Obesity (Silver Spring) 2007, 15(11):2817-2824.

17. Sharma AM: Obesity and cardiovascular risk. Growth Horm IGF Res 2003, A (13 Suppl):S10-17.

18. Fuller NJ: Comparison of abilities of various interpretations of bioelectrical impedance to predict reference method body composition assessment. Clin Nutr 1993, 12:236-242.

19. Kyle UG, Genton L, Slosman DO, Pichard C: Fat-free and fat mass percentiles in 5225 healthy subjects aged 15 to 98 years. Nutrition 2001, 17(7-8):534-541.

20. Pietrobelli A, Rubiano F, St-Onge MP, Heymsfield SB: New bioimpedance analysis system: improved phenotyping with whole-body analysis. Eur $J$ Clin Nutr 2004, 58(11):1479-1484.

21. Sluyter JD, Schaaf D, Scragg RK, Plank LD: Prediction of fatness by standing 8-electrode bioimpedance: a multiethnic adolescent population. Obesity (Silver Spring) 2010, 18(1):183-189.

22. Rush EC, Freitas I, Plank LD: Body size, body composition and fat distribution: comparative analysis of European, Maori, Pacific Island and Asian Indian adults. Br J Nutr 2009, 102(4):632-641.

23. Lear SA, Humphries KH, Kohli S, Chockalingam A, Frohlich JJ, Birmingham $\mathrm{CL}$ : Visceral adipose tissue accumulation differs according to ethnic background: results of the Multicultural Community Health Assessment Trial (M-CHAT). Am J Clin Nutr 2007, 86(2):353-359.

24. Wang D, Li Y, Lee SG, Wang L, Fan J, Zhang G, Wu J, Ji Y, Li S: Ethnic differences in body composition and obesity related risk factors: study in Chinese and white males living in China. PLoS One 2011, 6(5):e19835.

25. Berker D, Koparal S, Isik S, Pasaoglu L, Aydin Y, Erol K, Delibasi T, Guler S: Compatibility of different methods for the measurement of visceral fat in different body mass index strata. Diagn Interv Radiol 2010, 16(2):99-105.

26. Minderico CS, Silva AM, Keller K, Branco TL, Martins SS, Palmeira AL, Barata JT, Carnero EA, Rocha PM, Teixeira PJ, et al: Usefulness of different techniques for measuring body composition changes during weight loss in overweight and obese women. Br J Nutr 2008, 99(2):432-441.

27. Fakhrawi DH, Beeson L, Libanati C, Feleke D, Kim H, Quansah A, Darnell A Lammi-Keefe CJ, Cordero-Maclntyre Z: Comparison of body composition by bioelectrical impedance and dual-energy $x$-ray absorptiometry in overweight/obese postmenopausal women. J Clin Densitom 2009, 12(2):238-244

28. Deurenberg $P$, Yap M, van Staveren WA: Body mass index and percent body fat: a meta analysis among different ethnic groups. Int J Obes Relat Metab Disord 1998, 22(12):1164-1171.

29. Roth SM, Ferrell RF, Hurley BF: Strength training for the prevention and treatment of sarcopenia. J Nutr Health Aging 2000, 4(3):143-155.

30. Roubenoff R, Hughes VA: Sarcopenia: current concepts. J Gerontol A Biol Sci Med Sci 2000, 55(12):M716-724.

31. Soci-economic implications of aging in Sri Lanka an overview: oxford institute of ageing: working paper. Oxford; 2005

32. Stephen WC, Janssen I: Sarcopenic-obesity and cardiovascular disease risk in the elderly. J Nutr Health Aging 2009, 13(5):460-466.

\section{doi:10.1186/1471-2458-13-797}

Cite this article as: Ranasinghe et al:: Relationship between Body mass index (BMI) and body fat percentage, estimated by bioelectrical impedance, in a group of Sri Lankan adults: a cross sectional study. BMC Public Health 2013 13:797. 